\title{
A Model for the Global Economy
}

There's a lot of talk these days of unilateralism. Most notably, the most powerful and influential economy on our planet - or more accurately, its government - would prefer to cooperate less rather than more with its international partners.

You have to search far and wide for any expert who endorses this economic policy. With a few rare exceptions, you can give credence to the academic mainstream in scientific matters. And in matters relating to national economic isolation, mainstream opinion is unequivocal: the short-term benefits of going in alone at a national level will have harmful effects over the medium term - for all economies.

We in the lightweight design community can be glad that we are so far removed from any public mainstream and interests in our daily business that, generally speaking, we can base our decisions on objective facts and not emotions.
We can now see where this leads at every conference and every trade show dealing with the topic of lightweight design. The most interesting developments, the most practical processes and the innovative leaps in our discipline result almost exclusively from collaborative partnerships between several companies and research institutes.

It could be argued that it would scarcely be possible to achieve this at the interface of composite materials, metals, hybrids and different production methods in any other way than through the cooperating partners with different competences. But isn't the global economy also a complex structure?

So, is lightweight design a suitable model for the global economy? I don't think we are quite mainstream enough for that. Even so, it is still a fine model for the success of collective action and economic activity. 